\title{
CHARACTERIZATION OF NANO-PARTICLES DURING MG-AL-SPINEL- FORMATION CALCULATED BY MD- SIMULATIONS
}

Wilfried Wunderlich, Minoru Takahashi

Nagoya Institute of Technology, Ceramics Research Laboratory Tajimi

507-0071 Tajimi, Japan, e-mail: wi-wunder@ rocketmail.com

\begin{abstract}
If the particle-size reaches nanometer dimensions, the characterization even with HRTEM becomes extremely difficult, so that calculations are necessary. The Molecular Dynamics (MD)calculations of this work showed that the surface energy contribution of the amorphous shell of a nano-crystalline particle is relatively large compared to the crystalline core. The prediction from these calculation results is, that in the case of large particles the Spinel formation reaction is energetically preferred, while for the nano-particles the hydrolysis reaction is more favorable.
\end{abstract}

\section{INTRODUCTION}

Recent research activities focus on the processing of nano-particles, since they show special properties compared to usual material. The reason is the large amount of atoms in grain-boundary regions or surfaces [1], where the atoms leave their usual crystal lattice positions due to relaxation. From experimental observations it is well known, that nano-size particles show a faster progress of a solid-state reaction because the diffusion path for the reaction is shorter. On the other hand, the surface relaxations affect almost all atoms in the nano-size particle, so that the usual applied theory of the energy gain by forming a crystalline embryo of the new phase has to be examined. Indeed seeding enhances the Alumina formation [2] and many other physical effects occur in the slurry [3]. Better understanding is required and the first step reaching this goal is the calculation of surface energies for three different geometries. The second goal is to find out whether there is a nano-size effect due to the particle size in nano-meter scale. In this paper the reaction enthalpy for nano-size particles is calculated and compared to previous calculations on bulk specimens.

\section{CALCULATION METHOD}

Molecular dynamics (MD) is a suitable method for analyzing structural nano-size effects in ceramics and is also applied for ceramic surfaces in aqueous media [4]. The software "Moldy" [5] allows the use of the Bucking potential with a Morse part including the covalent bonding term and the bond stretch correction term. The potential parameters for $\mathrm{MgO}, \mathrm{Al}_{2} \mathrm{O}_{3}$, and $\mathrm{MgAl}_{2} \mathrm{O}_{4}$ fit well to macroscopic properties, especially lattice constants and thermal expansion coefficient of single crystal experiments [6]. Such MD-calculations have been successfully applied to several material science problems, e.g. [6-8]. The calculated energy values were normalized according to the number of mol of each phase.

Three different geometries were considered. At first, circular nano-particles were cut from structures of Periclas, Corundum, and Spinel crystals with sizes of $r=0.5,1$, and $2 \mathrm{~nm}$ and inserted in a vacant supercell with $20 \times 20 \times 20 \mathrm{~nm}^{3}$ (fig. 1). The number of mol were $38,242,1500$ for $\mathrm{MgO}$, 15, 101, 1000 for $\mathrm{Al}_{2} \mathrm{O}_{3}$, and 8, 168, $220(r=1.5 \mathrm{~nm})$ for $\mathrm{MgAl}_{2} \mathrm{O}_{4}$. Secondly, the pores with the 
same sizes were studied. These supercells $\left(5 \times 5 \times 5 \mathrm{~nm}^{3}\right)$ of the crystals contained about 15000 atoms. Thirdly, the layered geometry was used for surface calculations. The size of the supercell was $5.2 \times 3.3 \times 2 \mathrm{~nm}^{3}$ containing a layer with $2.5 \mathrm{~nm}$ thickness in the b-c-plane with either $1152 \mathrm{MgO}-$, $384 \mathrm{Al}_{2} \mathrm{O}_{3^{-}}$, or $288 \mathrm{MgAl}_{2} \mathrm{O}_{4}-\mathrm{mol}$. The crystallographic plane was (001) in $\mathrm{MgO}$ and $\mathrm{MgAl}_{2} \mathrm{O}_{4}$, and (0001) in the case of $\mathrm{Al}_{2} \mathrm{O}_{3}$. When creating the particles and layers by cutting the atoms, it was taken care that they are neutral in charge, which means the number of each atoms species has the same ratio than the corresponding single crystal.

The calculations were performed under constant pressure mode with periodic boundary conditions. The temperature of $0,300,500,1000$ or $1500 \mathrm{~K}$ was kept constant for $1 \mathrm{~ns}$. After initial relaxations the fluctuations of the energy and other values were very few, indicating that equilibrium has been reached.

The data were analyzed in two different ways. After dividing the total energy by the number of mol, these normalized values were calibrated to the thermodynamic enthalpy of each phase. This conversion can be performed, since the relation is linear in the range from 200 to $1500 \mathrm{~K}$ and it can be applied no matter in which geometry the atoms are arranged. The surface energy was calculated by dividing the energy difference of the surface calculation and the corresponding single crystal calculation through the area of the planar surface, or in the case of particles or pores with the radius $r$ the surface area $4 \pi r^{2}$.

\section{RESULTS AND DISCUSSION}

The Molecular Dynamics simulation results showed (fig. 2), that the enthalpy for each phase as a function of the temperature increases linearly. The values are the highest for nano-sized particles, while those of the layered geometry have middle, and the single crystal calculations the lowest energy. The surface energy decreases with the temperature (fig. 3). In the graphs the round symbols refer to the particles, the square symbols to the layered geometry, and the asterisk to literature values [4,9-11]. These values depend on the crystallographic orientation and in the case of $\mathrm{Al}_{2} \mathrm{O}_{3}$ the $\mathrm{Al}$-terminating surface has been found to have a larger energy than the O-terminating plane. The surface energies $\gamma$ as a function of the temperature $T$ was fitted by the equation: $\gamma=m T$ $+b$, where the slopes for the surface energy was determined as $m=2.5 * 10^{-4} \mathrm{Jm}^{-2} \mathrm{~K}^{-1}$ for the layered geometry in all three materials. These values correspond very well to previous calculations $[4,10]$, and the experimental values [9] for all three materials $\left(\mathrm{For}^{\mathrm{Al}} \mathrm{O}_{3}\right.$ also other data with a steeper slope $7.8 * 10^{-4} \mathrm{Jm}^{-2} \mathrm{~K}^{-1}$ are published [9]). The slopes for the nano-particles, however, are much smaller ( $\mathrm{MgO} 1 * 10^{-4}, \mathrm{Al}_{2} \mathrm{O}_{3} 0.2 * 10^{-4}, \mathrm{MgAl}_{2} \mathrm{O}_{4} 1.3 * 10^{-4} \mathrm{Jm}^{-2} \mathrm{~K}^{-1}$, respectively).

The enthalpy as a function of the logarithmic particle or pore radius is shown in fig. 4 , where the filled round symbols refer to the nano-particles, the open round symbols to the nano-pores and the square symbols to the layered geometry. The enthalpy values for each phase increase drastically, when the radius of the particles is below $10 \mathrm{~nm}$, while in the case of pores the values decrease. Comparing the three materials, the increase for nano-particles is moderate for Magnesia, steep for Alumina and very steep for the Spinel phase. The surface energy as a function of the radius is almost constant (fig. 5), as expected from the definition of the surface energy; however, the values for particles with a radius of $0.5 \mathrm{~nm}$ are exceptional high and do not follow this rule. The surface energy for the pores is lower than expected, probably due energy relaxations of atoms in a larger area than expected from the pure geometrically defined surface area of the round pores.

The increase of the enthalpy for nano-particles can be explained by the surface relaxations of the atoms. Atoms near the particle surface leave their low-energy crystalline lattice site, finding a relaxed position in order to fulfill the charge neutrality principle at the surface. The strong Coulomb forces push the atoms into an amorphous rim, which is about three monolayers thick according to the structural plots of the MD-calculation. Due to the small size these surface relaxations in nano-powder can affect the whole particle, and, hence, the energy contribution of the 
amorphous shell at a nano-crystalline particle less than $1 \mathrm{~nm}$ is comparatively large compared to the crystalline core. In the case of the layer geometry the calculated surface energy does not dependent on the size of the considered specimen as the surface energy is defined.

The molecular Dynamics simulations showed that in the case of nano-particles the energy is increasing, if the particle radius is below $1 \mathrm{~nm}$. This increase is in the case of Spinel very steep, hence the surface relaxations in this material are larger than in e.g. Magnesia. The conclusion from this result is, that in the case of strongly ionic materials, like $\mathrm{MgO}$, the nano-size effect is less; while for materials with higher covalent bonding fraction the surface relaxations are stronger.

The different slopes also imply, that in the case of nano-materials the phase-diagrams have to be revised. The prediction form these simulations is, that the hydrolysis reaction of Magnesia will not change much in the case of nano-particles, however, in the case of Spinel a higher energy is necessary to form this phase. Therefore, it is expected, that in the case of nano-particles in the slurry the hydrolysis reaction will occur before the Spinel formation.

This implies, that in the case of nano-particles phase diagrams might change. The AluminaMagnesia phase diagram [12] consists of a simple mixture of the binary Al- and Mg-rich ceramic alloys until at $350^{\circ} \mathrm{C}$ the Spinel reaction occurs. The Alumina phases transform as follows: Gibbsite is stable until $100^{\circ} \mathrm{C}$, than Boehmite up to $270^{\circ} \mathrm{C}$, Diaspore until $440^{\circ} \mathrm{C}$, until finally the corundum appears. In the case of Magnesia the hydrolysis reaction from Brucite to Periclas occurs at $600^{\circ} \mathrm{C}$. The prediction of the present MD-energy calculations is, that in the case of nano-particles the Spinel phase is less stable than Alumina or Magnesia, which means that the Spinel-formation reaction is retarded, when heating up the ceramic alloy. Therefore the Corundum phase is formed first before the Spinel phase. These predictions are based on the enthalpy change, while the entropy change is considered to be equal for all three phases.

\section{SUMMARY}

The MD-calculations of this work showed that the surface energy contribution of the amorphous shell of a nano-crystalline particle is comparatively large compared to the crystalline core, especially when the radius becomes less than $2 \mathrm{~nm}$. For nano-particles the number of involved atoms in the surface relaxation becomes too large, so that the surface energy is overestimated. The enthalpy calculation is a better concept, but is strongly temperature dependent. The enthalpy increases steeply for Spinel, moderately for Alumina and shallow for magnesia. The prediction from these calculation results is, that in the case of large particles the Spinel formation reaction is energetically preferred, while for the nano-particles the hydrolysis reaction is more favorable. This implies, that for nano-particles the phase-diagrams have to be revised. This research is the first step for understanding the interaction between particles used in the discrete element modeling, so that the processing path for ceramic nano-particles can be optimized.

\section{REFERENCES}

$1 \mathrm{~W}$. Wunderlich, Y. Ishida, R. Maurer, "HRTEM-Studies of the microstructure of nanocrystalline Palladium", Scripta Met., 24 403-404 (1990)

2 Roger B. Bagwell, Gary L. Messing "Effect of seeding and Water Vapor on the nucleation of $\alpha-\mathrm{Al}_{2} \mathrm{O}_{3}$ from $\gamma-\mathrm{Al}_{2} \mathrm{O}_{3}$ “, J.Am.Ceram.Soc. 82 [1] 825-32 (1999)

3 R.G. Horn, "Surface Forces and their action in Ceramic Materials", J.Am.Ceram.Soc. 73 [5] $1117-1135$ (1990)

4 Chang Ming Fang, Gijsbertus de With, Stephen C. Parker, "Computer Simulation of Dissociative Adsorption of Water on the Surfaces of Spinel $\mathrm{Mg}_{2} \mathrm{AlO}_{4}$ " J.Am.Ceram.Soc. 84 [7] 1553-58 (2001).

5. K. Refson, "Molecular Dynamics simulation of solid n-butane", Physica B 131 (1985) 256-266

6 S. Morooka, S.Zhang, T. Nishikawa, H. Awaji, "Potential Model Parameters for Molecular Dynamics Simulation of Alumina-Magnesia Systems", J. Cer. Soc. Jpn. 107 [12] 1225-8 (1999) 
7 W. Wunderlich, H. Awaji, "Molecular Dynamics Simulations of the fracture toughness of Sapphire", Journal of Material Design 22 [10] 53-59 (2000)

8 C.A.J. Fisher, H. Matsubara, "Oxide ion diffusion along grain boundaries in zirconia: A molecular dynamics study", Solid State Ionics 113-115 311-318 (1998)

9 P. Nikolopoulos, "Surface, grain-boundary and interfacial energies in $\mathrm{Al}_{2} \mathrm{O}_{3}$ and $\mathrm{Al}_{2} \mathrm{O}_{3}-\mathrm{Sn}$, $\mathrm{Al}_{2} \mathrm{O}_{3}$-Co systems”, J. Mat. Sci. 20 3993-4000 (1985).

10 H.Suzuki, H.Matsubara, J.Kishino, T.Kondoh, "Simulation of Surface and Grain Boundary Properties of Alumina by Molecular Dynamics Method", J.Cer.Soc.Jpn. 106 [12] 1215-22 (1998)

11 D.Wolf, "Structure of ionic interfaces from an absolutely convergent solution of the Madelung problem", Solid State Ionics 75 3-11 (1995)

12 D.M. Roy, R.Roy, E.F.Osborn, "Phase diagram $\mathrm{MgO}-\mathrm{Al}_{2} \mathrm{O}_{3}$ ”, Am.J.Sci. 251 [5] 347 (1953).
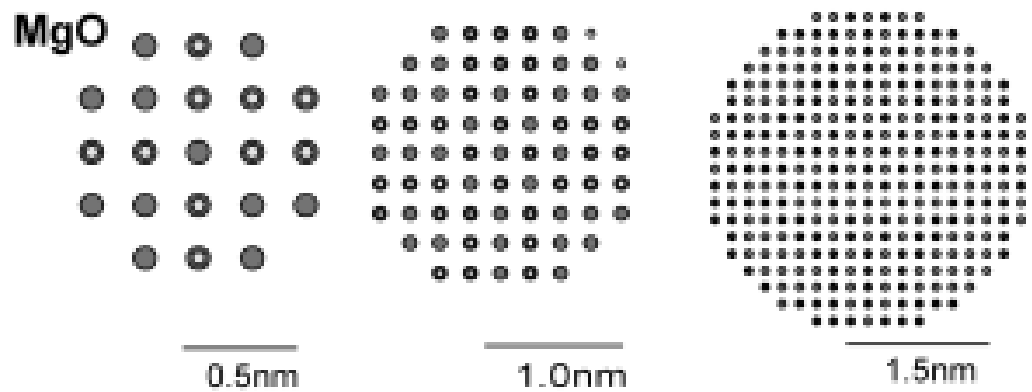

$\mathrm{Al}_{2} \mathrm{O}_{3}$

$0.5 \mathrm{~nm}$

1.Onm

$1.5 \mathrm{~nm}$
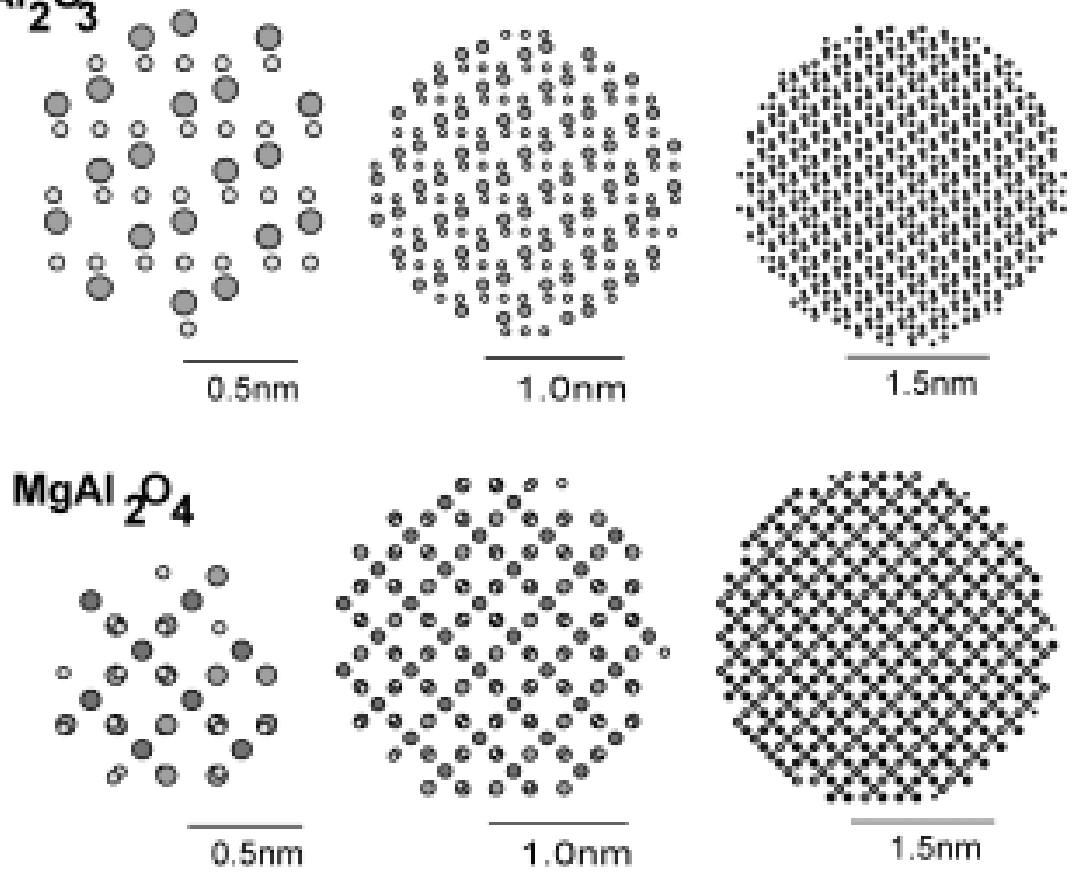

Fig. 1 Cross-section of nano-size particles used for three-dimensional MD-simulations. The small circles refer to Oxygen, the dark ones to Magnesia, the light one to Aluminum atoms. 

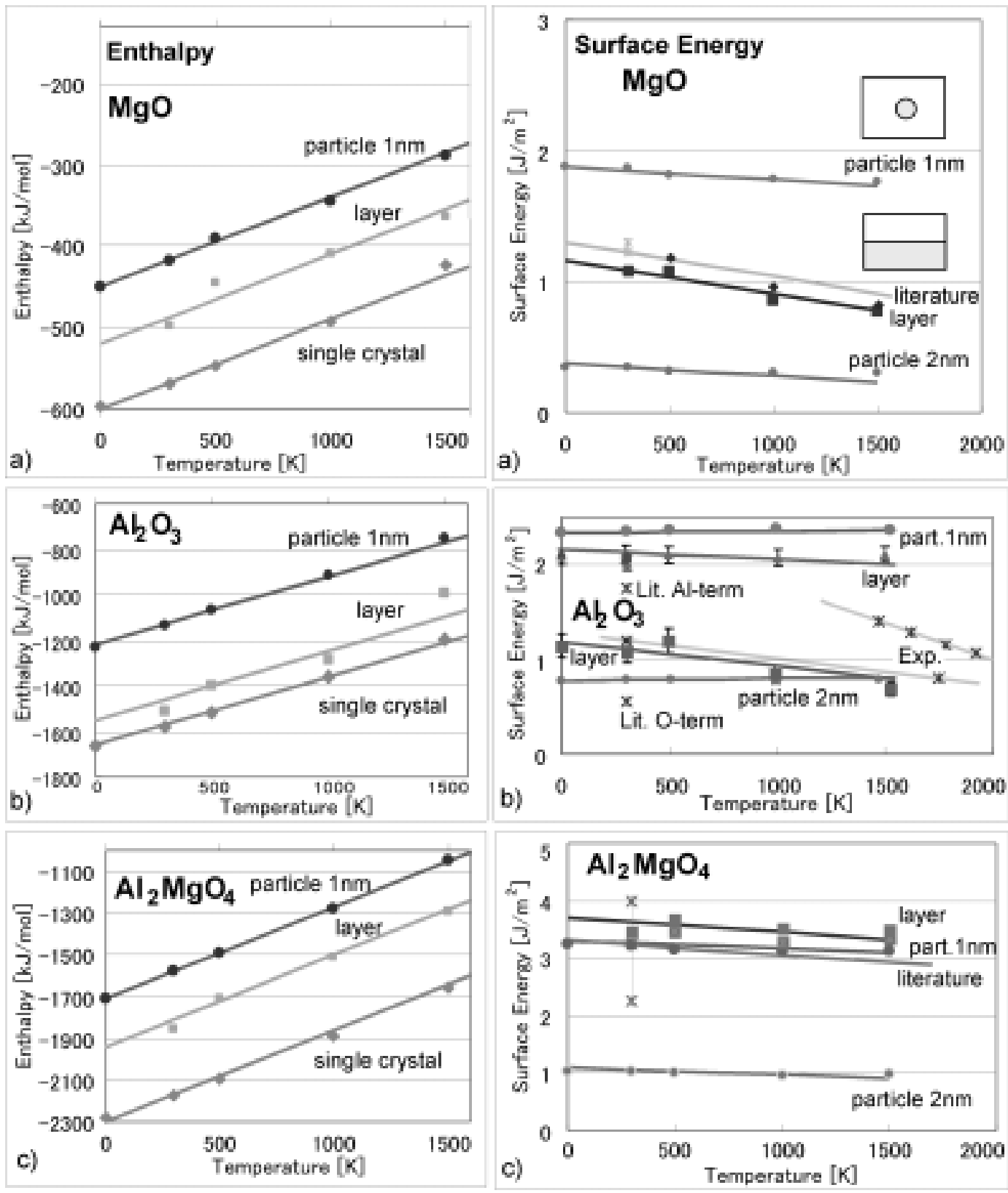

Fig. 2 Reaction Enthalpy as a function of the temperature for the three materials a) $\mathrm{MgO}$, b) $\mathrm{Al}_{2} \mathrm{O}_{3}$, and c) $\mathrm{Mg} \mathrm{Al}_{2} \mathrm{O}_{4}$ for $1 \mathrm{~nm}$-particles, layered geometry and single crystals.

Fig. 3 Surface energy as a function of the temperature for layered and particle geometry and literature values (marked with round, squared and asterisk symbols) for the three materials a) $\mathrm{MgO}$, b) $\mathrm{Al}_{2} \mathrm{O}_{3}$, and c) $\mathrm{Mg} \mathrm{Al}_{2} \mathrm{O}_{4}$. 

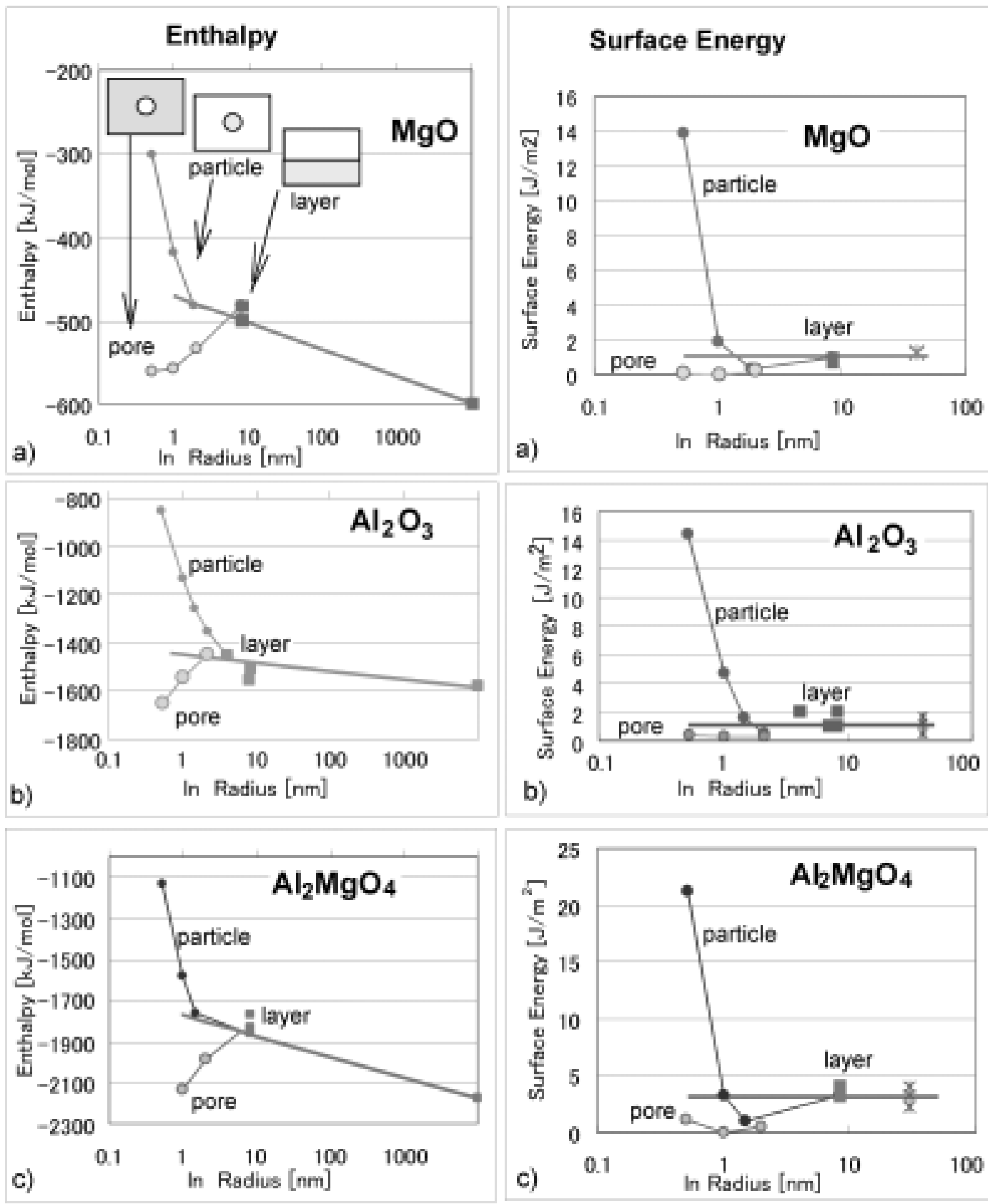

Fig. 4. Reaction enthalpy at $\mathrm{T}=300 \mathrm{~K}$ for the three materials as a function of the particle size. The filled and open, round symbols refer to round shaped particles and pores, the square

Fig. 5 Surface energy at $\mathrm{T}=300 \mathrm{~K}$ as a function of the particle size for the three materials a) $\mathrm{MgO}$, b) $\mathrm{Al}_{2} \mathrm{O}_{3}$, and c) $\mathrm{Mg} \mathrm{Al}_{2} \mathrm{O}_{4}$. The symbols symbols to layered geometry; a) $\mathrm{MgO}$, b) have the same meaning as in fig. 4 , the asteriks $\mathrm{Al}_{2} \mathrm{O}_{3}$, and c) $\mathrm{Mg} \mathrm{Al}_{2} \mathrm{O}_{4}$. mark the literature values. 